Cuadernos de $\mathrm{H}$ ideas

ISSN: 2313-9048

cuadernosdehideas@perio.unlp.edu.ar

Universidad Nacional de La Plata

Argentina

\title{
David Peña y la revista Atlántida: expresión de la intelectualidad y la cultura en torno al Centenario de la Revolución de Mayo (1911-1913)( $\left.{ }^{*}\right)$
}

Rubio García, Gonzalo

David Peña y la revista Atlántida: expresión de la intelectualidad y la cultura en torno al Centenario de la

Revolución de Mayo (1911-1913)(*)

Cuadernos de $\mathrm{H}$ ideas, vol. 12, núm. 12, 2018

Universidad Nacional de La Plata, Argentina

DOI: https://doi.org/10.24215/23139048e017

Esta obra está bajo una Licencia Creative Commons Atribución-NoComercial-SinDerivar 4.0 Internacional. 
Artículos

\title{
David Peña y la revista Atlántida: expresión de la intelectualidad y la cultura en torno al Centenario de la Revolución de Mayo (1911-1913)(*)
}

David Peña and the magazine Atlántida: expression of the intellectuality and culture around the Centennial of the May

Revolution (1911-1913)

\author{
Gonzalo Rubio García gonza_rubio@hotmail.com \\ Universidad de Buenos Aires, Argentina
}

Cuadernos de $\mathrm{H}$ ideas, vol. 12, núm. 12, 2018

Universidad Nacional de La Plata, Argentina

Recepción: 18 Julio 2018

Aprobación: 17 Septiembre 2018

DOI: https://

doi.org/10.24215/23139048e017

\section{BY-NC-ND}

Resumen: La revista Atlántida, dirigida por el historiador rosarino David Peña (1862-1930), se presentaba como una publicación de interés general, que tenía como objetivo crear puentes entre los intelectuales de renombre.Ofrecía un acercamiento a la cultura del período, priorizando los temas referidos a la historia y la política argentina, pero también artículos de economía, literatura y geografía, entre otros. En este trabajo realizamos un análisis general sobre dicha publicación -teniendo en cuenta la cantidad de ejemplares editados, los autores que allí dejaron su impronta, sus editores, etc.- profundizando la mirada en determinadas secciones con el objetivo de lograr un aproximación a las ideas que transmitía la revista y especialmente su director, considerando que guardaba características similares a otros emprendimientos editoriales de principios del siglo XX.

Palabras clave: David Peña, historia intelectual, prensa argentina, Centenario de la Revolución de Mayo.

Abstract: The magazine Atlántida, directed by the historian David Peña (1862-1930), was presented as a publication of general interest, which aimed to create bridges between renowned intellectuals. It offered an approach to the culture of the period, prioritizing the topics referred to to Argentine history and politics, but also articles on economics, literature and geography, among others. In this work we carry out a general analysis of this publication-taking into account the number of copies edited, the authors who left their mark, its editors, etc.- deepening the view in certain sections with the aim of achieving an approximation to ideas that transmitted the magazine and especially its director, considering that it had characteristics similar to other publishing ventures of the early twentieth century.

Keywords: David Peña, intellectual history, Argentine press, Centenary of May Revolution.

\section{Introducción}

La revista Atlántida, editada entre los años 1911 y 1913, fue dirigida por David Peña, un intelectual rosarino -abogado, periodista, historiador, político y dramaturgo- nacido el 10 de julio de 1862 y fallecido el 9 de abril de 1930. Protegido por Nicolás Avellaneda y Juan Bautista Alberdi, figuras argentinas con las que guardó una cercana relación de amistad, dedicó buena parte de sus obras a defender la postura de este último frente a las críticas políticas recibidas por Domingo Faustino Sarmiento 
y Bartolomé Mitre. A su vez, se destacó en el ambiente historiográfico por sus clases impartidas en la Universidad de Buenos Aires y La Plata, luego recopiladas y editadas en 1906, sobre Juan Facundo Quiroga, figura de la historia argentina a la cual reivindicó como contrapunto de otros caudillos federales, en especial, Juan Manuel de Rosas.(1)

En el caso particular de Atlántida, revista editada y financiada en Buenos Aires por Coni hermanos, se presentaba como una publicación innovadora, de "carácter general", que buscaba realizar un acercamiento a la cultura del periodo, insertarse en el ambiente cultural argentino de principios de siglo XX y dar lugar a distintos temas referidos a la historia argentina.(2) Como afirmaron Héctor Lafleur, Sergio Provenzano y Fernando Alonso, Peña se propuso "armonizar en sintesis representativa, todo lo que las letras del pais ofrecian de perdurable en el presente y en el pasado".(3) Con notoria preferencia por la investigación histórica, entonces, constituyó un valioso intento de aproximación entre lo que había sido y lo que era la República.(4)

El contexto cultural de principios del siglo XX daba lugar a publicaciones como Atlántida. En la época del Centenario patrio, gran parte de los intelectuales y políticos argentinos consideraban a la Argentina como un país pujante, con grandes posibilidades económicas y características raciales únicas, capaz de liderar el escenario político latinoamericano frente al creciente poder de Estados Unidos.(5) Sin embargo, la inevitable pregunta sobre las raíces y costumbres culturales argentinas se había convertido en un importante tópico de análisis en el mundo intelectual, en especial por la llegada de muchísimos inmigrantes que ponían en jaque las concepciones -ligeramente- establecidas por los ciudadanos más antiguos.(6) En el pensamiento de las elites, comenzó a estimarse insuficiente respetar las leyes nacionales para considerarse argentino, sino que se debía estar imbuido de una cultura nacional.(7)

La problemática consistía en saber cuáles eran las características que debía tomar esa cultura. En un sentido simplificado, los intelectuales se dividieron en dos vertientes: aquellos que entendían la formación de la identidad nacional a partir de la mezcla de culturas y quienes buscaban en un supuesto pasado criollo las características de los argentinos.(8) La cuestión por la definición de la identidad nacional luego transmutó en una disputa simbólica que movilizó al Estado para fomentar una idea determinada de nación mediante simbolismos, estatuas, la conformación de una galería de hombres célebres, etc.(9)

En el caso particular de Peña, debe ser considerado como un intelectual, funcional al Estado, cuyas obras influyeron en las representaciones e imágenes que formaron los individuos de principios del siglo XX sobre sí mismos. Pertenece a la caracterización de "intelectual-político", es decir, a un clima de época en el que solía confundirse -aunque no en la totalidad de los casos- el ambiente cultural con el ámbito de poder, subordinándose los letrados a las necesidades del Estado.(10) Era común que la intelectualidad y los funcionarios políticos aparecieran asociados, formato que hacía de los pensadores un engranaje más del aparato de gobierno. Ciertos intelectuales-políticos pasaron a ser los prototipos de 
una generación hacedora de la Nación.(11) Sin embargo, dicha postura no implica considerar a todos bajo un mismo prisma ideológico sino, simplemente, destacar los mecanismos de profesionalización que algunos encontraban: buscaban destacarse en el mundo científico pero, al mismo tiempo, tener injerencia en las funciones del Estado y entremezclar ambas facetas de forma complementaria.(12)

En este punto, nos vemos obligados a definir a los intelectuales: teniendo en cuenta los diferentes usos que el término recibió en el último tercio del siglo XIX, nos referimos a los hombres de ideas que interpelaban a la opinión pública, mediante discursos y ensayos, con una misión cultural determinada, es decir, quienes tuvieron acceso a un "conjunto de posiciones, prácticas y destrezas letradas".(13) Su papel en el terreno social estaba recortado por la configuración histórica de su tiempo y por aquellos otros pensadores con los que dialogaban sobre diferentes problemáticas.(14)

En relación a los intelectuales, debemos considerar en nuestro escrito aquellos estudios sobre las redes intelectuales que nos permitirán comprender con mayor precisión la función cultural que perseguía Atlántida.(15) Si bien no encontramos una definición consensuada sobre aquello que implica una red intelectual, en principio podemos definirlas mediante el conjunto de personas ocupadas en la producción y difusión del conocimiento "que se comunican en razón de su actividad profesional a lo largo de los años".(16) La importancia de considerar los estudios sobre las redes radica en la posibilidad de poder medir los mecanismos de funcionamiento mediante los que operaban y el "complejo sistema de vinculos y la circulación de bienes y servicios, materiales e inmateriales" que establecían sus miembros mediante distintos espacios culturales y simbólicos.(17)

De todas formas, debemos tener en cuenta que la búsqueda de un vínculo no implicaba un voto de confianza y solidaridad entre los intelectuales. Por dicha razón, no debemos sobreestimar el alcance que pudieron haber tenido las redes para el progreso de las ciencias. Aunque, de todas formas, dicha noción guarda un gran potencial para comprender los mecanismos mediante los que se transfieren y progresan las ideas, en especial si utilizamos sus parámetros explicativos en relación al concepto de influencia intelectual,(18) pues, a pesar de las críticas que ha recibido por parte de algunos autores, dicha noción nos ayudará a entender la procedencia de ciertas ideas en torno a Atlántida y las posteriores repercusiones que generaron en otros pensadores.(19)

Se torna, entonces, interesante analizar la revista Atlántida, pues, como sucede con otras publicaciones, permite visualizar las tensiones del campo cultural en el período estudiado y la intersección con los proyectos individuales y grupales, mostrando las preocupaciones estéticas, políticas y de identidad a comienzos del siglo XX.(20) Dichas cuestiones serán analizada en las siguientes páginas de este escrito, haciendo especial hincapié en algunas de las secciones de la revista como: "Fisionomía del país", "Crónica del Centenario" y la publicación de la obra teatral "Dorrego", escrita por Peña. 
Analizaremos la revista como un producto cultural complejo, donde no sólo atenderemos al contenido, sino también a la revista en tanto objeto material, cuestión que implica tomar en cuenta sus formas iconográficas y discursivas, al igual que sus códigos, sensibilidades, estructuras y formas de captar un mayor público.(21) Buscaremos descifrar la constelación de rasgos que constituyó a la revista, siendo un fenómeno particular, para mostrar la impronta de Peña como emprendedor gráfico a través de Atlántida.

Siguiendo la anterior lógica, nuestro objetivo, más allá de la descripción de la revista, sus ejes estructurales, el análisis de las ideas que allí se discutían y el impacto que tuvo en el mundo cultural argentino, es dar cuenta de un momento cultural específico en torno a su creación: el del Centenario patrio. Dicho período histórico se caracterizaba por el firme arraigo que la cultura científica había cobrado en la comunidad intelectual, es decir: el conjunto de intervenciones teóricas que reconocían el prestigio de la ciencia como forma de legitimación de sus opiniones. Surgieron nuevas figuras sociales y profesionales, se crearon nuevos lugares de trabajo, se definieron vocabularios y aparatos críticos compartidos para el análisis social que lograron crear una imagen determinada sobre lo que era y determinaba a la ciencia.(22)

En referencia a los objetivos planteados, sugerimos en primer lugar, que la apuesta editorial de Peña fue poco novedosa en el clima de época del Centenario, pues sólo trataba de imitar a aquellas revistas de carácter científico que habían surgido desde finales del siglo XIX, agregando artículos de interés general que hicieran referencia al ámbito cultural.

En segundo lugar, consideramos que el principal objetivo de Peña respecto a Atlántida era lograr un acercamiento entre los intelectuales del interior del país y los porteños -distanciados por los localismos políticos todavía vigentes a principios del siglo XX- utilizando la revista como un punto de unión entre distintos individuos relacionados al ambiente de la ciencia y la cultura, con el objetivo de establecer entre ellos lazos de confianza que permitieran elaborar proyectos comunes y cultivar el intelecto.

En tercer lugar, afirmamos que Peña buscó exaltar las virtudes que consideraba propias de la Argentina para mostrar la pujanza de la Nación y su crecimiento a la par de los principales países del mundo.

\section{Atlántida: un faro de cultura al servicio de los intelectuales}

La revista Atlántida tuvo una corta existencia. Como mencionamos anteriormente, comenzó a editarse en enero de 1911. Sin embargo, en diciembre de 1913, con la edición del número treinta y seis, la revista pasó a ser un vehículo de publicidad del Ateneo Nacional -institución dedicada al cultivo de las Letras y las artes, fundada por iniciativa del mismo David Peña el 25 de octubre de aquel año-, dando lugar al último número de la publicación tal y como se la conocía. Desapareció por completo en 1914, con el número 39, posiblemente, por falta de fondos económicos para continuar la empresa. De todas formas, entre los 
años 1911 y 1913, Atlántida se entregó mensualmente, como había sido planificado. Cada publicación constaba de ciento sesenta páginas, las que encuadernadas trimestralmente formaban tomos de trescientas ochenta carillas. Así, la publicación estuvo comprendida por cuatro tomos anuales (sumaron un total de doce) con treinta y seis entregas.(23)

Desde muy temprana edad, Peña había formado la idea de fundar un periódico. En una de sus innumerables charlas con Nicolás Avellaneda, el ex presidente había indagado sobre el objetivo de iniciar tal empresa, pues un diario, afirmaba, se fundaba "para actuar en politica", con un determinado fin social y/o una "campaña determinada". Si bien, dicha charla desincentivó las intenciones de Peña, tiempo después su iniciativa tuvo lugar mediante publicaciones como Época, Revista Argentina, Nueva Época, Diario Nuevo, Las Novedades, y finalmente, Atlántida.(24)

El objetivo de la empresa intelectual fue expresado por Peña: "revistas de esta indole no se fundan con un propósito actual. Aspiran a ser útiles en el lento transcurrir de los años como lo son hoy las publicaciones máso menos similares que se registran en nuestra bibliografia".(25) El director creía necesario realizar una publicación que exteriorizara la "latente vida del espiritu" argentino y la hiciera fructífera en la práctica ofreciendo sus páginas a "todos los espiritus", sin más restricción que la "sana moral y el bien decir", que buscaran mover el entendimiento de las ideas generales para lograr un aporte intelectual a la Nación.(26) De allí surgía el papel de Peña como articulador y mediador dentro de las relaciones que mantenía con otros escritores para lograr su participación en Atlántida.

Siguiendo un punto de vista nacional, Peña buscaba abarcar las manifestaciones intelectuales de todo el país, dejando de lado la dicotomía que existía en la época entre las revistas provinciales y aquellas que estaban circunscriptas en torno a la ciudad de Buenos Aires: aspiraba mostrar las características geográficas, económicas y políticas de la totalidad del país. Incluso, guardaba una postura americanista, pues, argumentando la falta de conocimiento que había en el continente sobre sus características y los pensadores del territorio, Peña proponía unir a los "pueblos fraternos, del mismo origen", entrelazando las "almas de la América en la infinita expresión de su aliento intelectual'.(27) Su principal aspiración era que los intelectuales de toda la Argentina tuvieran un punto de contacto a través de Atlántida: una referencia que lograra generar una comunidad y cultivar el progreso científico y cultural.(28) De todas formas, la anterior idea fue sostenida por diferentes publicaciones de la época que se caracterizaban por la divulgación de la cultura y los avances científicos, buscando establecerse en el complejo mundo editorial de principios del siglo XX como instituciones en torno a las cuales giraran algunas de las plumas más reconocidas del país.(29)

Nuestro autor consideraba que los científicos y hombres de letras debían ser liberados de las restricciones establecidas por la política nacional, una de las razones por la que Atlántida había sido creada.(30) Peña era consciente de la importancia que cobraba en la explicación de los fenómenos sociales la "simpatía o antipatía" que podían guardar aquellos que producían relatos. El temperamento personal del escritor, afirmó, es 
"susceptible de obedecer a causas que se ligan directamente con el espiritu", razón por la que las opiniones son todas diferentes, pues distintos son los criterios que las juzgan. Acercarse a la verdad, concluyó, podía ser una ilusión, pues la consideraba un "convencionalismo a su turno".(31)

La anteriormente mencionada postura de Peña también había sido expuesta por Vicente Quesada en La Revista del Paraná, publicación que consideraba influencia ineludible para cualquier iniciativa editorial de índole científica, pues buscó establecer en Atlántida parámetros similares a los seguidos por su colega en el siglo XIX.(32) Editados sus ocho números entre 1860 y 1861, La Revista del Paraná había nacido como un espacio de sociabilidad intelectual que trataba de conformar un ámbito para el "estudio de la historia de las provincias y un foro de debate que estuviera alejado de la polémica ardiente y apasionada de la prensa política", siendo, además, tratadas las cuestiones vinculadas con la legislación y el análisis de las doctrinas de la economía política.(33)

Peña reprodujo en Atlántida algunos fragmentos que formarían parte de las posteriormente publicadas memorias de Quesada, aquellas que, a su vez, contenían párrafos editados en La Revista del Paraná. Allí, dicho autor expresó los deseos que había tenido para la publicación decimonónica: "fundar un periódico que sirviera de exponente a la vida intelectual de las provincias", logrando comunicar, en el "terreno tranquilo de las bellas letras", a los distintos intelectuales argentinos, y respondiera al calificativo de bárbaros y caudillos que, afirmaba, la prensa porteña había adjudicado a los provincianos. El autor pretendía formar un círculo literario nacional que se consagrara al estudio del país y lo diera a conocer en todos sus aspectos, respondiendo a la "injuria y a la calumnia" porteñas con "la cultura y el amor al estudio".(34)

Quesada, según afirmaba, buscaba expresar un "patriotismo desinteresado" para "producir el bien y trabajar por la patria", rasgo que compartió Peña al momento de explicar los motivos para lanzar su revista.(35) Ambos caracterizaban a gran parte de los intelectuales como seres pensantes que buscaban dar su aporte a la Nación sin retribuciones políticas o económicas. Bajo dicha lógica, las publicaciones buscaban influir en el futuro argentino para marcar el camino que debían seguir las generaciones siguientes, siempre destacando su imparcialidad al momento de establecer sus opiniones y consejos patrióticos.(36)

Bajo la anteriormente mencionada lógica de la "imparcialidad cientifica”, Quesada pretendía conocer la sociedad colonial evocando testimonios de los testigos que podían dar un relato auténtico.(37) De hecho, agregó un sentido provincial a los relatos que mostraba en su revista, pues entendía que, tratándose de la historia argentina, debía “darla a conocer en lo relativo a cada localidad, porque conocida la de cada una de las provincias, se formaria sin esfuerzo la nacional'.(38) A diferencia de la Revista del Paraná, Atlántida no sólo dio importancia a la idea de reconstruir en sus páginas la historia nacional, sino que también trató con muchísima importancia otros aspectos culturales, científicos, jurídicos y hasta teatrales -aquellos que trataremos a continuación- que daban a la 
publicación una impronta muy completa sobre las ideas que circulaban a principios del siglo XX.

Más allá de los escritos de Quesada publicados en Atlántida, la revista guardaba una materialidad y presencia concreta como objeto, es decir, un programa estético, que se vislumbraba por los recursos tecnológicos utilizados y la relevancia dada a las fotografías en sus páginas. Si bien predominaba el discurso textual, cuestión lógica dado el carácter intelectual de la publicación, las ilustraciones o fotografías funcionaban como unidades informativas visuales que acompañaban a los textos para brindar un mayor contenido descriptivo sobre los temas tratados.(39)

La postura intelectual seguida por Peña dio cierta trascendencia a la revista, cuestión por la cual gozó de un gran prestigio en el ámbito cultural. Muchas de las afinidades por él forjadas entre los escritores, espontáneas en la mayoría de los casos, se habían generado con anterioridad a la publicación de Atlántida. Sin embargo, las redes que tendió para obtener fuentes originales, los últimos avances científicos en materia de filosofía, psicología y otras disciplinas, generaron una conglomeración de importantes intelectuales en torno a la revista: Ricardo Rojas, Juan Julián Lastra, Mario Bravo, Marco M. Avellaneda, José Ingenieros, Tomás Amadeo, Gustavo Caraballo, Andrés Chabrillón, José María Sáenz Valiente, Juan P. Ramos, Enrique Banchs, Carlos A. Leumann, Roberto F. Giusti, Carlos Ibarguren, Carlos O. Bunge, Estanislao S. Zeballos y Ricardo Levene, entre otros.

Los escritos de la revista buscaban analizar las ideas de los hombres que predominaban en el ambiente intelectual. Por dicha razón, había un apartado especial, denominado "Nuestros colaboradores", en el que se describía brevemente a los intelectuales y figuras que habían colaborado o sido analizados en Atlántida. No siempre eran nombres reconocidos los que aparecían en sus páginas, sino que se daba lugar a intelectuales de diferentes disciplinas que muchas veces se destacaban en sus ambientes, pero eran desconocidos para el público general. Sólo para nombrar algunos ejemplos, la sección hizo lugar, entre otros, a Vicente Quesada - "uno de nuestros grandes escritores", destacado por ser un "obrero del pensamiento"-, pero también a Pedro Alurralde -ministro de gobierno en la provincia de Tucumán, al igual que senador y diputado- y Wilhelm Keiper, un pedagogo prusiano, profesor de la Universidad de Buenos Aires, que se había destacado por investigar las metodologías de enseñanza utilizadas en los profesorados y escuelas.(40)

Siguiendo la lógica con que, en parte, la revista exponía y analizaba las ideas de los intelectuales es que Peña dedicó un artículo de Atlántida para analizar las obras de Nietzsche. El escrito describía el contexto de época en que había surgido la figura del filósofo: una nación alemana recientemente unificada que concentraba sus "fuerzas materiales e intelectuales para mantenerse a la altura alcanzada". Buscaba mostrar las poesías líricas de Nietzsche, menos conocidas que sus ideas filosóficas.(41)

Dichos escritos se caracterizaban por expresar explícitamente los sentimientos del autor. Su poesía, según afirmaba el anteriormente citado y autor del artículo Wilhelm Keiper, no pretendía elevarse sobre 
la impresión del momento a una esfera general, sino que Nietzsche buscaba expresar sus sentimientos mediante las palabras en una forma entendible y sensible para lograr la compresión del lector sobre su estado de ánimo. Según el autor, todos los escritos citados habían compartido la anterior característica, pues las cuestiones filosóficas que planteaba no buscaban formar un ensayo objetivo, sino que eran documentos "fieles de su experiencia propia".(42) Keiper nombró brevemente las características que guardaban las obras del filósofo: "muchas veces podemos observar directamente, como la situación en que se encuentra influye en su pensamiento y presta forma y carne a sus errantes ideas".(43)

Bajo la misma lógica seguida en el artículo de Keiper, Peña también dio lugar en Atlántida a la pluma de José ingenieros.(44) El reconocido autor escribió un artículo sobre psicología: sus funcionamientos, definiciones y derivaciones. Todo el escrito se encontraba atravesado por el positivismo científico, incluso la definición sobre el concepto de psicología, cercano a las funciones biológicas de los seres vivos y su "evolución socio genética y ontogenética". Afirmaba: "es una ciencia natural que estudia las funciones psíquicas de los organismos vivientes".(45) Incluso, el trascendental intelectual se aventuró a estudiar en dicho artículo a la filosofía, disciplina que caracterizó en torno a las ciencias, pues, aseguraba, estaba casi subordinada a ellas.(46) Más allá de esa cuestión, la publicación de dicho artículo nos muestra la variada difusión de temas y el acercamiento a materias poco comunes para la época -al menos en los ámbitos cotidianos y populares de esparcimiento- que efectuaba Peña hacia el público no especializado.

Como afirmamos anteriormente, la revista no se ocupaba únicamente de la política y la historia argentina, sino que buscaba mostrar diferentes manifestaciones de la cultura general. La serie de artículos denominados como "Crónicas del Centenario" cumplía dicho cometido. Fueron pensados para dar nota de los monumentos, medallas y celebraciones que se realizaron al conmemorar los 100 años de la Revolución de Mayo.

En el primer escrito de "Crónicas del Centenario", por ejemplo, se daba cuenta e imagen de las medallas acuñadas en oro para los altos funcionarios, diputados, senadores y jefes eclesiásticos, entre otros cargos importantes del Estado. Allí también se describía el monumento que se realizaría para conmemorar el acontecimiento patrio, próximo a emplazarse entre la Avenida de Mayo y la calle Reconquista: un obelisco que contendría la hasta entonces erigida Pirámide de Mayo.(47) El artículo explicaba, con mucho patriotismo, que la ancha base del monumento indicaba "la raiz misma de la nacionalidad argentina", aquella que había comenzado "en los días gloriosos de la semana de Mayo de 1810".(48) Pocas veces, continuaba el escrito, "se ha unido con mejor forma la escultura a la arquitectura -dos hermanas gemelas-para eternizar la mayor gloria del pais".(49)

La serie de artículos también hizo lugar a los monumentos que se construirían en el interior del país, como aquel que se emplazaría para conmemorar a la figura de Dean Gregorio Funes en la provincia de Córdoba. De hecho, se explicaba la razón por la cual dicha figura histórica 
era de relevancia para la memoria del país.(50) Todas las descripciones, a su vez, fueron ilustradas con una gran cantidad de imágenes -incluían los retratos de los homenajeados y una breve descripción-, que daban cuenta de los planos, ornamentos y formas que cobrarían los proyectos destacados.

Desde el punto de vista cultural, también se dedicaron varias palabras a la Exposición Internacional de Arte del Centenario - realizada entre mayo y noviembre de 1910 en distintos barrios del norte de la ciudad de Buenos Aires- en una serie de artículos denominados "Exposición Internacional de Arte en la República Argentina”. En el primer artículo se destacaba el pleno éxito de la exposición, realizada con motivo de las fiestas del Centenario de la Revolución de 1810, pues había recibido convocatoria de diversas naciones europeas y americanas. (51)

La postura editorial tenía un marcado objetivo por posicionara la Argentina dentro del concierto de naciones importantes. Podemos pensar, entonces, la descripción de la exposición como otro intento por parte de Peña de exaltar las virtudes argentinas y mostrar al país en un status similar al de las potencias mundiales.(52) Desde la revista se afirmaba que Buenos Aires podía ser conceptualizada como una plaza comercial y un "centro artístico digno de ser apreciado por Europa", habiendo servido la exposición para mostrar el "progreso alcanzado por el país en las ramas de la cultural espiritual".(53)

Las referencias a la exposición eran especialmente descriptivas. No sólo se detallaba su ubicación en Buenos Aires, sino que también se ilustraba la distribución de pabellones mediante un mapa que ordenaba los puestos de los países según su emplazamiento.(54) Además de describir a las naciones participantes - Austria-Hungría, Bélgica, Chile, Estados Unidos, Francia, entre otras- y el número total de obras expuestas -teniendo en cuenta las pinturas, esculturas, aguas fuertes y artículos de arte, sumaban 2375-, el artículo caracterizaba los puestos de cada país y su contenido. Bajo dicha lógica, se describía, por ejemplo, la exhibición de las obras alemanas en las salas XXVI, XXVII y XX. Dicha Nación había presentado 105 pinturas y 29 esculturas en distintos recintos con decoración sencilla: ostentaba "muros tapizados con tela de color claro", "pisos cubiertos por caminos de coco" y "diseminadas con profesión y buen gusto, numerosas plantas de helechos y algas".(55)

Siguiendo la faceta cultural de la revista, Peña también dio lugar a la publicación de distintas poesías inéditas de Ricardo Rojas, autor al que destacaba por sus logros políticos, pero especialmente por haber concebido uno "de los libros más intensos sobre la enseñanza civica bajo el nombre de La Restauración Nacionalista”.(56) Tenía el mérito, afirmaban desde la redacción, de haber puesto su espíritu en contacto con las cuestiones de valor para inspirar a la nacionalidad argentina.(57)

También debemos destacar la publicación de la obra teatral titulada Dorrego. Siendo Peña un autor ecléctico desde el punto de vista teatral, pues abordaba distintos géneros como la comedia de costumbres, el drama patológico y las obras políticas, en Dorrego siguió una línea, delimitada con anterioridad en otras obras, para llevar al teatro la historia de algunas 
figuras argentinas que no habían cobrado demasiada trascendencia. Esta idea había tenido lugar con el estreno de la obra teatral Facundo (1906), cuyo relato distaba mucho de la imagen presentada sobre el caudillo por Sarmiento. Peña presentaba a Quiroga como un líder popular, respetado en el interior, cuya principal premisa era la imposición del federalismo. La obra suscitó comentarios y críticas de toda índole, llegando, incluso, a entablar Jorge Mitre una polémica con Peña desde sus columnas del diario La Nación.(58)

Debido al éxito que había obtenido con Facundo, tiempo después, en 1909, estrenó Dorrego.(59) Tal como pudimos observar en las páginas de Atlántida, Peña mostró a Manuel Dorrego como un líder federal amenazado por la conspiración política, preocupado por la unión de las provincias del Río de la Plata, cuyos perseguidores y verdugos no creían posible instaurar un sistema federal en la región.(60)

Más allá de la obra, obtuvo críticas positivas incluso desde una perspectiva historiográfica. Los cuadros y escenas del cuarto acto, sentenciaba Carlos María Urien, uno de sus críticos, se ajustaban a "un juego escénico lógico y fueron compuestos con estricta sujeción a la verdad histórica".(61) Peña, continuó, había estudiado "concienzudamente la obra, la acción real, la representación de las escenas en que se dividen los cuatros actos del drama", pues era una "reproducción fiel de la arquitectura del tiempo, del mensaje y costumbres de la época".(62)

Como mencionamos anteriormente, la revista buscaba mostrar la historia argentina mediante la reproducción de distintas fuentes que podrían ser útiles para la investigación y clarificación de algunos sucesos importantes del pasado.(63) La pluralidad de voces era tan amplia que se publicaban biografías y epístolas de diversos intelectuales y políticos en los que se criticaba a distintas figuras del siglo XIX. Este fue el caso del artículo "El acuerdo de San Nicolás".(64) Dicho escrito, realizado por Vicente Fidel López, narraba las circunstancias y sucesos que atravesaron la firma del acuerdo. Por haber defendido el pacto, afirmó, se había enajenado el afecto de Buenos Aires, como le pasara a Alberdi, llamado igualmente el "abogado de la confederación".(65)

La voz de López intervino en la polémica respecto a Dalmacio Vélez Sarsfield, Valentín Alsina y Francisco Pico, pues había rechazado el supuesto derecho de los porteños a imponer sus condiciones al resto del país. Las páginas publicadas en Atlántida correspondían a una respuesta realizada por López a Alsina y Vélez Sarsfield, pues se sentía injuriado por ellos en relación a la conferencia privada que en mayo de 1852 había tenido lugar en Palermo respecto al acuerdo.(66)

López buscaba establecer su posición entre los que afirmaban, por igual, que se había pronunciado a favor y en contra del proyecto. En principio se mostró como un "ardiente partidario" en defensa de la ley de la capitalización y la creación de un ejército nacional. Entendía las preocupaciones dominantes de Buenos Aires, pero consideraba que su postura política era un "obstáculo fatal para una buena organización nacional”. Por esa razón, buscó demostrar su participación en los debates en torno al escrito - "no estuve callado, como dice Alsina", afirmó- y dejar 
establecida su posición en contra del proyecto presentado por Pujol, autor del texto preliminar que se buscaba imponer y que fuera luego modificado.(67)

En segundo lugar, buscaba desmentir a Alsina, pues, como Rosas, afirmó, no quería organizar a las provincias. Él buscaba ser Gobernador de Buenos Aires, adulando a Justo José de Urquiza e incentivando sus deseos de investirse con el poder nacional, pero terminó por generar una revolución cuyo "pretexto" fue el Acuerdo de San Nicolás, "como lo habría sido cualquier otro”.(68) Alsina y Vélez Sarsfield, destacó López, jamás podrán explicar por qué razón "se opusieron a que hubiese paz perpetua, unión permanente y amistad estrecha entre las provincias argentinas", pues sólo defendían su propio interés en una situación económica y comercial adversa para el país.(69) En nombre de la Provincia de Buenos Aires, afirmó, ambos se opusieron al Acuerdo de San Nicolás y a la libre navegación de los ríos, cuyas medidas centuplicaron "la masa de mercaderias que se removia de su mercado".(70)

Algo similar sucedió con el artículo "Domingo F. Sarmiento" -figura que Peña había puesto en entredicho por su relato sobre Quirogaque reproducía una epístola de Nicolás Avellaneda dirigida al doctor Vallejos en 1869.(71) Dichas páginas eran presentadas como un material inédito del ex presidente y buscaban dejar testimonio sobre aquello que a él importaba destacar sobre la personalidad de Sarmiento y sus cualidades.(72)

Según Avellaneda, Sarmiento no sólo había explicado las razones de conflicto político que había en Argentina, sino que era recordado como el "apóstol" del liberalismo en América del Sur: el primero en pedir la libre navegación de los ríos, la supresión del pasaporte y toda traba fiscal, para que los hombres, al igual que las mercaderías e ideas, pudiesen moverse libremente. En el escrito, Avellaneda también destacaba la propaganda realizada por Sarmiento a favor de la educación primaria y la denostación contra los orilleros y gauchos, convirtiéndose así, afirmaba, en un inspirador de su "fervor intelectual y patriótico".(73)

El mayor mérito de Sarmiento, continuó Avellaneda, había radicado en ser el verdadero expositor del régimen federal y las ideas estadounidenses de la libertad, explicando las instituciones norteamericanas a los argentinos. Según el autor, Sarmiento declaraba que la proclamación de los derecho de los pueblos y del hombre pertenecían a los viejos y fervientes puritanos norteamericanos, no a la franceses.(74) Para aquel, explicaba Avellaneda, la revolución francesa se apoyaba en una "base falsa y deleznable”, pues dicho pueblo había guiado a su país al abismo.(75) Bajo esa lógica, en concordancia con las ideas de Sarmiento, el análisis de Avellaneda abundaba en críticas a la cultura política francesa y exaltaciones a las formas sociales alemanas y estadounidenses. (76)

Otra de las apuestas de Peña para mostrar y exaltar las características argentinas encontró cause mediante los artículos denominados "Fisionomía del País", que analizaban, en especial, la historia de las instituciones y la política nacional. Consideraba que la grandeza del país radicaba en el correcto funcionamiento de sus organismos públicos, un 
pensamiento común en la dirigencia política de la época. Los hombres, afirmaba, eran "meros accidentes al lado de esas instituciones", razón por la que no debía permitirse que fueran manipuladas por los referentes políticos.(77) Dicho postulado, continuaba el artículo, era el que Roque Sáenz Peña había propuesto para llevar adelante en el país, pues se encontraba "libre de influencias personalistas" que pudieran perjudicar de forma nociva a la "moral que toda republica exige".(78)

Mediante los diferentes artículos denominados como "Fisionomía del País", se apoyaba la idea de dar a los partidos políticos garantías reales de libertad electoral, "restableciendo en todos los ámbitos del pais el imperio de la libertad institucional y devolviendo al pueblo la preciosa función de dirigir sus destinos y elegir sus propios funcionarios".(79) Peña consideraba que el gobierno del presidente Sáenz Peña podía lograr establecer un sistema electoral sencillo y honesto que familiarizara al ciudadano con el uso de sus derechos políticos, cuestión que le preocupaba, pues era elemental para establecer el tipo de republicanismo democrático que el intelectual rosarino anhelaba instaurar en Argentina. Fiel a sus ideas, Peña consideraba que ayudar al primer mandatario en dicha tarea contribuiría a la "salud de las instituciones y de la patria".(80)

En la serie de artículos, comparó los problemas de la historia argentina con aquellos que había en la política de principios del siglo XX. Según su consideración, en la época de Bernardino Rivadavia, figura de la cual no guardaba las positivas consideraciones que había otorgado a Sáenz Peña, los hombres de Buenos Aires habían tramitado la "entrega de todo elpais al protectorado de un monarca extranjero" debido al malestar político, pues el primer presidente del país, pudiendo haber sido "el gran vínculo de unión entre las provincias y Buenos Aires", no sentía atracción hacia ellas, un aspecto que profundamente lamentaba Peña.(81)

Como pudimos observar, al momento de editar Atlántida, la problemática entre las provincias y Buenos Aires seguía ocupando un lugar importante en el pensamiento de Peña, tal como había dejado en evidencia en su escrito Juan Facundo Quiroga. Por dicho motivo, realizó un resumen histórico sobre dicha cuestión según el tratamiento que le habían dado los políticos del siglo XIX. En especial, destacaba la figura de Manuel Dorrego, un "conocedor del alma criolla", que se había acercado a las figuras políticas del interior, siendo destituido, afirmó, "por el más porteño tipo de todas las generaciones". Rosas habría mantenido el entredicho entre provincianos y porteños, "queriendo o sin querer", mientras que a Urquiza le correspondía el "honor indiscutible" de haber sancionado la Constitución que luego se convirtiera en la ley fundamental de toda la república. Mitre sólo habría conseguido reunir a las provincias mediante el uso de la fuerza, mientras que Sarmiento tampoco habría logrado "adueñarse del alma de las provincias para fundirlas con el alma de Buenos Aires en un solo crisol". La obra de unión entre los argentinos, afirmaba, había comenzado con la presidencia de Avellaneda y su ley de capitalización de Buenos Aires y continuaba al momento en que Atlántida fue concebida.(82) 
El resumen realizado por Peña buscaba mostrar las atribuciones y posibilidades políticas que podía tener un presidente, pues, consideraba, era quien más podía robustecer o debilitar el sentimiento de amor entre los argentinos. Bajo esa lógica, recomendaba a Sáenz Peña entregarse a las "corrientes populares de la vida del interior", pues si viajaba para lograr "entrar dentro de la psicología nacional", tendría "positiva grandeza y paz en su gobierno". Consideraba que mientras más se acercara el presidente a las provincias, más se debilitaría el "feudalismo" que, según creía, existía en la Nación.(83)

En una óptica similar estaban las ideas de la segunda entrega de "Fisionomía del país", pues daban cuenta de la historia del Congreso, siguiendo la idea de analizar la historia argentina mediante sus instituciones y conflictos políticos. El artículo analizaba dichos espacios de debate a partir de las reuniones revolucionarias de 1810, momento en que se habían echado los "cimientos del parlamentarismo argentino" y "el pensamiento del pais en forma hablada", es decir, las bases sobre la idea de nación Argentina.(84) Aquella historia de la institución sólo era la introducción para realizar un análisis sobre la situación del Congreso a principios del siglo XX. Dicho estudio incluía la descripción de sus funciones, su estructura jurídica, y la mención de algunos de sus más destacados miembros como Joaquín V. González, Marco Avellaneda o Benito Villanueva, todos representantes del senado.(85)

Para la tercera entrega, Peña eligió publicar una carta de Roque Sáenz Peña al Gobernador de Córdoba escrita en 1911. Dicha elección buscaba mostrar la postura del presidente, quien prefería no intervenir en la política de las provincias, fuera gobernada por aliados u opositores, mientras no se viera atacado el republicanismo. El ex presidente buscaba establecer una "acción positiva de los partidos orgánicos y responsables", pues, temer el triunfo de los partidos desafectos, destacaba Peña, era disminuir el volumen de situaciones y de los partidos que les presten apoyo, declarando incompatible su existencia con el régimen de las mayorías legales. Para Sáenz Peña, dicha situación significaría que las minorías gobernarían en el país a despecho de las mayorías, mientras que su propósito era "hacer de las elecciones, por obra del convencimiento, una función regular de la vida republicana". Contra ese panorama luchaba Peña, quien, cautivado por las iniciativas del ex presidente, buscaba dar lugar en la revista a sus palabras como forma de expresar sus propias ideas. (86)

\section{Conclusión}

Como hemos mencionado al comienzo del escrito, la revista Atlántida buscó mostrar los conocimientos científicos y culturales que se estaban desarrollando a principios del siglo XX en el ámbito intelectual, especialmente en Argentina y el continente americano. Una de las ideas principales de Peña era exponer el pensamiento de una generación de intelectuales, la del Centenario, para sentar precedente y una base para los futuros investigadores y figuras relacionadas al ámbito cultural, 
haciendo especial hincapié en aquellos escritores del interior del país que, quizá por cuestiones políticas, no cobraban trascendencia en el ámbito porteño. Principalmente, la publicación se autodefinía como un elemento destinado a unir puentes o redes entre los intelectuales, darles un lugar de pertenencia y respaldo editorial.

Sin embargo, al poco tiempo, Peña pudo vislumbrar que la publicación no trascendería dentro del cúmulo de revistas editadas a principios del siglo XX. Dicha cuestión acarreaba la inevitable preocupación por el sustento económico que hacía peligrar el futuro de Atlántida. A pesar de todo, la revista logró subsistir tres años que sirvieron para marcar la impronta de una época y dejar editadas las ideas que circulaban en ese entonces. En ese sentido, como hemos podido analizar, la publicación se ha tornado en una fuente de información importante para lograr reconstruir una imagen cultural sobre el período del Centenario.

La revista Atlántida siguió los parámetros de otras revistas que buscaban mostrar un carácter científico, como la anteriormente mencionada Revista del Paraná, pero añadiendo facetas culturales y jurídicas que hacían muy interesantes y completas sus páginas para el público, logrando un abanico temático más amplio que el de otras publicaciones. De todas formas, en relación a La Revista del Paraná, ambas publicaciones buscaban alejarse de las polémicas de la prensa política, cultivar el conocimiento y acercar posiciones entre los diferentes intelectuales, planteándose como instituciones que resumían los avances científicos de la época.

Al mismo tiempo, otro de los objetivos centrales de la revista fue mostrar las características - políticas, geográficas, históricas, jurídicas, etc.- que tenía la Argentina, mostrando al país como un faro de progreso que estaba a la par de las principales potencias mundiales, en especial Estados Unidos. Dicha postura guarda sentido, pues recién con la Gran Depresión de 1929, las consideraciones que tenían los argentinos sobre sí mismos cambiaron drásticamente debido a la crisis económica y política en que se vio inmerso el país.

Desde el plano historiográfico, Peña expresó en Atlántida un punto de vista similar sobre la historia argentina al que había detentado en su obra sobre Quiroga. Su principal cometido en esa área fue desestimar las ideas negativas que se adjudicaban a ciertas figuras del federalismo, en especial las de origen provincial, razón por la que presentó a Quiroga y Dorrego como héroes patrios que bregaban por la organización constitucional del país, a diferencia de Rosas, una figura denostada en sus relatos. A su vez, la preferencia del director por dar lugar a los temas históricos quedó plasmada en la diversa cantidad de escritos sobre el pasado argentino que se trataron en sus números, algunos de los que hemos dado cuenta a lo largo del artículo.

Más allá de sus ideas historiográficas, en sus últimos números, la revista sobrellevó con grandeza su penosa situación financiera, haciendo un gran esfuerzo por lograr sus apariciones mensuales. A pesar del malestar económico, Atlántida no dejó de mostrar en sus páginas un variado y completo contenido sobre distintas especialidades de la labor científica 
y las artes, razón que nos indujo a considerar a su director como un ejemplo de la generosa iniciativa puesta al servicio de la cultural que ciertos intelectuales tenían a principios del siglo XX.

\section{Notas}

$\left.{ }^{*}\right)$ El presente trabajo constituye un avance de mi tesis doctoral sobre los nacionalismos argentinos ligados al revisionismo histórico, donde estudio, entre otras figuras, las ideas que guardaba el intelectual David Peña.

(1)Algunas de estas cuestiones fueron abordadas en: Rubio García, Gonzalo y Rubio García, María Sol. "De 'vindicadores' a 'revisionistas'. (Re) interpretaciones de la historia en la primera mitad del siglo XX. David Peña y Raúl Scalabrini Ortiz", Ponencia presentada en la VIo Jornada de discusión de avances de investigación en Historia Argentina: fuentes, problemas, métodos, Rosario, Universidad Católica Argentina, 2016, pp. 11-16. Recuperado de (29/03/2018): http://www.institutohistori a.com.ar/uploadsarchivos/actas_digitales_vi_jornada_de_avances_2016.pdf También, ver: Buchbinder, Pablo. Historia de la Facultad de Filosofía y Letras, Universidad de Buenos Aires, Buenos Aires, Eudeba, 1997, pp. 62-65 y Rubio García, María Sol. “David Peña, amigo y defensor de Alberdi", Todo es Historia, № 580, Buenos Aires, 2015, pp. 62-71.

(2)Peña, David. "Prospecto", Atlántida, Buenos Aires, Coni Hermanos, 1911, tomo I, p. 5.

(3)Lafleur, Hector, et al. Las revistas literarias argentinas, 1893-1967, Buenos Aires, El 8 vo loco, 2006, p. 55.

(4)Según destacó Leopoldo Kanner, en Atlántida fue donde mejor se vieron reflejadas sus ideas, aunque no hayan sido siempre estrictamente historiográficas. De hecho, el autor destacó los escritos que mostraban las supuestas ideas biologicistas de Peña y una interesante postura sobre la historia, pues la caracterizaba como un proceso de duración, siendo, para el autor decimonónico, sinónimos ambos conceptos: la "Historia argentina" no era, bibliográficamente hablando, "el montón de libros que han aparecido". Incluso, Kanner afirmó un supuesto concepto "aristocrátizante" en los escritos de Peña y destacó el valor que daba al Derecho para descubrir la forma en que habían acontecido los procesos históricos. De todas formas, otros autores, como Fernando Devoto y Pablo Buchbinder, han estudiado la figura de Peña destacando la importancia de su Juan Facundo Quiroga (1906) para la historiografía del período y la labor que realizó en las distintas instituciones donde impartió sus clases. Ver: Kanner, Lepoldo. Ideas historiográficas de David Peña, Santa Fe, Imprente de la UNL, 1957, pp. 19-20; Kroeber, Clifton. Rosas y la revisión de la historia argentina, Buenos Aires, Fondo Editor Argentino, 1964, pp. 22-23 y 45-52; Devoto, Fernando y Pagano, Nora. Historia de la historiografia argentina, Buenos Aires, Sudamericana, 2009, p. 204; Buchbinder, Pablo. Op. Cit., p. 63; Micheletti, María Gabriela. "Facundo Quiroga rehabilitado". Una aproximación al contexto de producción, repercusiones y aportes historiográficos del libro de David Peña (1906)", Boletín del Instituto de Historia Argentina y Americana "Dr. Emilio Ravignani", № 42, Buenos Aires, 2015, pp. 125-153.

(5)Ver: Gálvez, Manuel. El diario de Gabriel Quiroga. Opiniones sobre la vida argentina, Buenos Aires, Taurus, 2001, pp. 74-75 y 86-87 y Lugones, Leopoldo. El payador. Tomo primero, Hijo de la Pampa, Buenos Aires, Otero \& Co, 1916, pp. 22-23 y 28.

(6)Ante los conflictos del período, el Estado afrontó algunas medidas de control social que estaban inspiradas en una gran cantidad de estudios analíticos sobre la "cuestión social" de los inmigrantes, el desarrollo del país y su cultura. Tenían en cuenta, entre otras cuestiones, aquellas problemáticas que giraban en torno a la "raza" y la conformación biológica de la población. Ver: Zimmermann, Eduardo. Los liberales reformistas. La 
cuestión social en la Argentina 1890-1916, Buenos Aires, Sudamericana, 1994, pp. 91-107.

(7)Terán, Oscar. Historia de las ideas en la Argentina. Diez lecciones iniciales, 1810-1980, Buenos Aires, Siglo XXI, 2008, p. 172.

(8)Ibidem, p. 172.

(9)Ver: Bertoni, Lilia Ana. Cosmopolitas y nacionalistas. La construcción de la nacionalidad argentina a finales del siglo XIX, Buenos Aires, Fondo de cultura económica, 2001.

(10)Entre otros, ver: Buchbinder, Pablo. "Vínculos privados, instituciones públicas y reglas profesionales en los orígenes de la historiografía argentina", Boletín del Instituto de Historia Argentina y Americana "Dr. Emilio Ravignani", No. 13, Buenos Aires, 1996, pp. 73-80 y Bruno, Paula. "Biografía e Historia de los intelectuales. Balance y reflexiones sobre la vida cultural argentina entre 1860 y 1910”, Literatura y Lingüistica, No 36, Buenos Aires, 2017, pp. 19-36. Recuperado de (02/04/2018) https://scielo.conicyt.cl/ pdf/lyl/n36/0716-5811-lyl-36-00019.pdf

(11)Este también fue el caso de Adolfo Saldías, un intelectual-político que entremezcló su militancia en el Partido Autonomista y luego en la Unión Cívica Radical con las funciones que cumplió como Ministro de Obras Públicas (1898) y Vicegobernador de la Provincia de Buenos Aires (1902). Al igual que Peña, se dedicó al estudio de la historia con su célebre obra denominada Historia de Rosas, luego retitulada Historia de la Confederación Argentina (1881-1883). Allí, Saldías se encargó de reivindicar la imagen de Juan Manuel de Rosas y establecer distintas posturas políticas sobre su figura que luego rescataron autores revisionistas como Julio Irazusta. Ver: Saldías, Adolfo. Historia de la Confederación Argentina. Rozas y el juicio histórico, Buenos Aires, Editorial Americana, 1945 e Irazusta, Julio. Adolfo Saldías, Buenos Aires, Ediciones Culturales Argentinas, 1964.

(12)Para el caso, Peña ocupó algunos puestos políticos en torno a la década de 1890: fue asesor del Ministerio de Obras Públicas y legislador en la provincia de Santa Fe.

(13)En el análisis sobre los relatos de los intelectuales y la historia de las ideas, resulta imprescindible, además, desnaturalizar algunos de los supuestos actuales, pues hay conceptos naturalizados en nuestra vida cotidiana -nación, patria, y muchos otros que podrían funcionar como ejemplos- cuyo significado era distinto en el pasado. Ver: Chiaramonte, José Carlos. Usos politicos de la historia. Lenguaje de clases y revisionismo histórico, Buenos Aires, Sudamericana, 2013, p. 277; Palti, José Elías. ¿Las ideas fuera de lugar? Estudios y debates en torno a la historia politico-intelectual latinoamericana, Buenos Aires, Prometeo, 2014, p. 14; Altamirano, Carlos. Para un programa de historia intelectual y otros ensayos, Buenos Aires, Siglo XXI, 2005, p. 10 y Terán, Op. Cit, p. 11.

(14)Altamirano, Carlos. Intelectuales. Notas de investigación sobre una tribu inquieta, Buenos Aires, Siglo XXI, 2013, pp. 17, 73 y 113-115.

(15)Para este tema, ver: Lanzillota, María de los Ángeles y Salomón Tarquini, Claudia. "Palabras preliminaries", en Lanzillota, María de los Ángeles y Salomón Tarquini, Claudia. Redes intelectuales, itinerarios e identidades regionales en Argentina (siglo XX), Rosario, Prohistoria, 2015, pp. 9-12.

(16) Devés-Valdés, Eduardo. Redes intelectuales en América Latina. Hacia la constitución de una comunidad intelectual, Santiago de Chile, Universidad Santiago de Chile, 2007, pp. 30 y 218.

(17)Casaús Arzu, María. "Prologo", en Devés-Valdés, Eduardo. Redes intelectuales en América Latina. Hacia la constitución de una comunidad intelectual, Santiago de Chile, Universidad Santiago de Chile, 2007, pp. 21-28. 
(18)Para este tema, ver: Dosse, François. La marcha de las ideas. Historia de los intelectuales. Historia intelectual, Valencia, Universidad de Valencia, 2007, pp. 56-60; Skinner, Quentin. Visions of Politics: Volume I: Regarding Method, Cambridge, Cambridge University Press, 2002, pp. 17-37 y Iglesias, Daniel. "El aporte de las redes sociales a la historia intelectual”, Historia y Espacio, Vol. 13, No 49, 2017, pp. 17-37. Recuperado de (18/04/2018): http://revistas.univalle.edu.co/index.php/historia_y_es pacio/article/view/5880/8153

(19)Eduardo Devés-Valdes afirmó que la noción de redes intelectuales es más eficaz para analizar la circulación de ideas que el concepto de "influencia", en especial, por la "verticalidad" en la transmisión de información que le adjudicó. Ver: Devés-Valdes, Eduardo. Op. Cit., pp. 33-34.

(20)Para este tema, ver: Pita, Alexandra y Grillo, María del Carmen. "Revistas culturales y redes intelectuales: una aproximación metodológica”, Temas de nuestra américa, $\mathrm{N}^{\circ}$. 54, México, Universidad de Colima, 2013, pp. 177-194. Recuperado de (25/04/2018): http://www.revistas.una.ac.cr/index.php/tdna/article/view/6338/6354; Beigel, María Fernanda. "Las revistas culturales como documentos de la historia latinoamericana", Utopia y Praxis latinoamericana, No 20, Venezuela, Universidad de Zulia, 2003, pp. 104-115. Recuperado de (02/04/2018) http://www.redalyc.org/articulo.oa?id=27902 007 y Altamirano, Carlos y Sarlo, Beatriz. Literatura y sociedad, Buenos Aires, Hachette, 1983.

(21)Como afirmó Alejandro Eujanian, las revistas, en especial las literarias, deseaban ser leídas y conocidas, pretendían circular y trascender, pero a su vez, huían a la masividad, aunque no dudaban en invocar, en más de una ocasión, "al público como responsable de su efímera vida”, siendo, además, sus lectores los miembros de la corporación a la que pertenecían los escritores, intelectuales y artistas que en ellas escribían. Ver: Eujanian, Alejandro. Historia de las Revistas Argentinas, 1900-1950, Buenos Aires, Asociación de Editores de Revistas, 1999, p. 57; Sarlo, Beatriz. El imperio de los sentimientos. Narraciones de circulación periódica en la Argentina 1917-1927, Buenos Aires, Catálogos, 1985; Girbal-Blacha, Noemí y Quatrocchi-Woisson, Diana. Cuando opinar es actuar.Revistas argentinas del siglo XX, Buenos Aires, Academia Nacional de la Historia, 1999, p. 25 y Torres, Alejandra. "La argentina del centenario en Mundial Magazine de Rubén Darío", Olivar, Revista de Literatura y Cultura Españolas, No 14, La Plata, FaHCE, 2009, pp. 93-10. Recuperado (02/03/2018): http://www.memoria.fahc e.unlp.edu.ar/art_revistas/pr.4500/pr.4500.pdf

(22)Ver: Bruno, Paula. Op. Cit., p. 28 y Terán, Oscar. Vida intelectual en el Buenos Aires fin-de-siglo (1880-1910): derivas de la cultura cientifica, Buenos Aires, Fondo de Cultura Económica, 2000, pp. 9-10.

(23)Auza, Néstor Tomás. Estudio e indice general de El Plata Cientifico y Literario (1854-4855) y Atlántida (1911-1913), Buenos Aires, Universidad del Salvador, 1968, p. $46-47$.

(24)Cometta Mazoni, Aida. "David Peña", en Noticias para la Historia del Teatro Nacional, Buenos Aires, Imprenta de la Universidad, 1937, pp. 33-71.

(25)Peña, David. Op. Cit., pp. 7-8.

(26)Ibidem, p. 6.

(27) Ibidem, pp. 6-7.

(28)Dicha postura también fue compartida en la década de 1910 por Rubén Darío, el poeta nicaragüense que, mediante la revista Mundial Magazine, logró establecer lazos entre los intelectuales de distintas partes del mundo. Ver: AUTOR. "Los nacionalistas argentinos en Mundial Magazine: los casos de Leopoldo Lugones y Manuel Gálvez", RESGESTA, No 53, Rosario, Pontificia Universidad Católica Argentina, pp. 1-5, 
Recuperado de (05/04/2018): http://200.16.86.39/index.php/RGES/article/view/89 $3 / 859$

(29)Entre 1900 y 1941 se editaron alrededor de 1039 revistas en Buenos Aires y 637 en el interior del país. Dicha cantidad de publicaciones había sido incentivada por los avances y desarrollos tecnológicos en el campo de las imprentas que permitieron mayores tiradas, mejoras en la calidad de imagen y la alternancia de texto escrito con imágenes. Ver: Eujanian, Alejandro. Op. Cit., p. 30.

(30) Peña, David. Op. Cit., p. 6.

(31)Peña, David. "Fisionomía del país”, Atlántida, Buenos Aires, Coni Hermanos, 1911, tomo I, p. 143.

(32)La Revista del Paraná editada por la alternativa de unidad nacional que auspiciaba el gobierno de la Confederación, daba preferencia al estudio de la historia nacional. Dejó de editarse, posiblemente, por la coyuntura política signada por las expectativas generadas en torno a la unificación nacional tras la batalla de Cepeda y la firma del Pacto de San José de Flores. Ver: Eujanian, Alejandro. "Por una historia nacional desde las provincias. El frustrado proyecto de Vicente Quesada en La Revista del Paraná", Cuadernos del Sur, No 39, Universidad Nacional del Sur, 2012, pp. 75-77 y Buchbinder, Pablo. Los Quesada: Letras, ciencias y politica en la Argentina, 1850-1934, Buenos Aires, Edhasa, 2012, p. 82.

(33)Ibidem, pp. 79-81 y Quesada, Vicente. "La vida intelectual en las provincias", Atlántida, Buenos Aires, Coni Hermanos, 1911, tomo I, p. 321.

(34)Ibidem, pp. 339 y 342.

(35)Ibidem, p. 334.

(36) Ibidem, pp. 343-344.

(37)Buchbinder, Pablo. Op. Cit., pp. 82-83.

(38)Quesada, Vicente. Op. Cit., p. 349.

(39)Freund, Gisele. La fotografía como documento social, Barcelona, Gili, 1997; "Nuestros colaboradores", Atlántida, Buenos Aires, Coni Hermanos, 1911, tomo II, pp. 155-160 y "Crónicas del Centenario", Atlántida, Buenos Aires, Coni Hermanos, 1911, tomo I, pp. 400-438.

(40) "Nuestros colaboradores", Atlántida, Buenos Aires, Coni Hermanos, 1911, tomo II, pp. 475-476 y "Nuestros colaboradores", Atlántida, Buenos Aires, Coni Hermanos, 1911, tomo I, pp. 157-161.

(41)Keiper, Wilhelm. "Nietzsche, poeta", Atlántida, Buenos Aires, Coni Hermanos, 1911, tomo I, p. 44.

(42) Ibidem, p. 48

(43)Ibidem, p. 52.

(44) Respecto a Ingenieros, Peña publicó también parte de su obra El hombre mediocre, publicada en 1913. Ver: Ingenieros, José. El hombre mediocre, Buenos Aires, Anaconda, 1957, pp. 101-106 e Ingenieros, José. "El éxito y la Gloria", Antlántida, Buenos Aires, Coni Hermanos, 1911, tomo III, pp. 409-416.

(45)Ver: Ingenieros, José. "La psicología genética. Bases biológicas de la psicología contemporánea”, Atlántida, Buenos Aires, Coni Hermanos, tomo II, p. 161.

(46)Ibídem, p. 172. 
(47)“Crónicas del Centenario”, Atlántida, Buenos Aires, Coni Hermanos, 1911, tomo I, pp. 121-124.

(48) Ibidem, p. 123.

(49) Ibidem, p. 124.

(50)“Crónicas del Centenario", Atlántida, Buenos Aires, Coni Hermanos, 1911, tomo II, pp. 88-91.

(51)Armellini, Federico. "Exposición internacional de arte en la República Argentina”, Atlántida, Buenos Aires, Coni Hermanos, 1911, tomo I, p. 139.

(52)Para este tema es conveniente considerar las pretensiones argentinas respecto a los países americanos a principios del siglo XX y su postura frente al panamericanismo y el latinoamericanismo. Ver: Morgenfeld, Leandro. Vecinos en conflicto: Argentina frente a Estados Unidos en las conferencias panamericanas (1880-1955), Buenos Aires, Continente, 2011 y Rapoport, Mario. Gran Bretaña, Estados Unidos y las clases dirigentes argentinas: 1940-1945, Buenos Aires, Universidad de Belgrano, 1980.

(53)Armellini, Federico. Op. Cit., p. 142.

(54)Ibidem, p. 140.

(55) Ibidem, p. 119.

(56)Peña se encargó de abarcar una gran cantidad de representaciones literarias en su revista, razón por la que se publicaban poemas como "La Divina Comedia" - para el caso, fue transcripta una versión revisada por G. A. Scartazzini- y "El Oro", cuyo autor fue Ricardo del Campo. Ver: Besio Moreno, Nicolás. "La divina comedia, según la revisión del texto de G. A. Scartazzini”, Atlántida, Buenos Aires, Coni Hermanos, 1911, tomo II, pp. 400-405 y Del Campo, Ricardo. "El Oro", Atlántida, Buenos Aires, Coni Hermanos, 1911, tomo II, p. 378.

(57)“Nuestros colaboradores” (tomo I) Op. Cit., p. 160 y Rojas, Ricardo. "Balada”, Atlántida, Buenos Aires, Coni Hermanos, 1911, tomo II, pp. 116-120.

(58)Cometta Mazoni, Aida. Op. Cit., p. 56.

(59)El autor continuó estrenando obras teatrales con temática históricas a lo largo de su carrera: en 1917 estrenó Liniers y en 1924, Alvear.

(60)Peña, David. “Dorrego. Drama histórico en cuatro actos”, Atlántida, Buenos Aires, Coni Hermanos, 1911, tomo III, pp. 266-280 y 438-457.

(61)Urien, Carlos. María. Dorrego: Drama histórico en cuatro actos del Dr. David Peña. Juicio histórico, Buenos Aires, Coni Hermanos, 1912, p. 14.

(62)Ibidem, p. 16.

(63)Respecto a la historia y la política argentina, Peña dio lugar en Atlántida para explicar los sucesos y antecedentes de la Guerra del Paraguay. Dicho punto se explica por la relación de amistad que guardaba con Juan B. Alberdi y la trascendencia como opositor que este había tenido en dicho conflicto bélico. Ver: Fernández, Teófilo. "Guerra del Paraguay; sus antecedes”, Atlántida, Buenos Aires, Coni Hermanos, 1911, tomo II, pp. 336-358.

(64)El Acuerdo de San Nicolás (31 de mayo de 1852), precedente de la Constitución de 1853 , buscaba organizar a las provincias. Fue ratificado por trece de ellas, excepto Buenos Aires.

(65)Ver: "Nuestros colaboradores" (tomo I) Op. Cit., p. 156. 
(66)Ver: López, Vicente Fidel. “El acuerdo de San Nicolás”, Atlántida, Buenos Aires, Coni Hermanos, 1911, tomo I, pp. 9 y 12.

(67)Ibidem, pp. 14-17.

(68)Ibidem, p. 21.

(69)Ibidem, pp. 24-25 y 27-30.

(70)Ibidem, p. 31.

(71)En otra oportunidad, Peña también reprodujo una serie de epístolas inéditas de Alberdi a las que tuvo acceso. Dichas cartas fueron publicadas con el mismo objetivo que las de Avellaneda: buscaban mostrar e incentivar distintos tipos de fuentes históricas para enriquecer los debates intelectuales sobre las figuras argentinas. Ver: Peña David. Juan Facundo Quiroga, Buenos Aires, Coni Hermanos, 1906, pp.10-11, 12 y 19-21; "Cartas familiares del Dr. Juan Bautista Alberdi (1875-1878)”, Atlántida, Buenos Aires, Coni Hermanos, 1911, tomo III, pp. 161-183.

(72)Avellaneda, Nicolás. "Domingo F. Sarmiento. Carta al Doctor Vallejo”, Atlántida, Buenos Aires, Coni Hermanos, tomo I, p. 42 y "Nuestros colaboradores" (tomo I) Op. Cit., p. 157.

(73)Avellaneda, Nicolás, Op. Cit., pp. 34-35.

(74)Ibidem, pp. 35-36.

(75)Ibidem, p. 37.

(76)Ibidem, p. 39.

(77) Peña, David. “Fisionomía...” Op. Cit., p. 146.

(78)Ibidem, p. 148.

(79)Alurralde, Pedro. "Fisionomía del país", Atlántida, Buenos Aires, Coni Hermanos, 1911, tomo II, p. 148.

(80)Peña, David. “Fisionomía...” Op. Cit., p. 149.

(81)Ibidem, p. 150.

(82) Ibidem, p. 152.

(83) Ibidem, pp. 152-153.

(84)Para este tema tan controversial, ver: Donghi, Tulio Halperín. Una nación para el desierto argentino, Buenos Aires, Centro editor de América Latina, 1982; Chiaramonte, José Carlos. Ciudades, provincias, Estados. Orígenes de la Nación Argentina (1800-1846), Buenos Aires, Ariel, 1997 y Souto, Nora y Wasserman, Fabián. "Nación”, en Goldman, Noemí (comp.), Lenguaje y Revolución. Conceptos politicos clave en el Río de la Plata, 1780-1850, Buenos Aires, Prometeo, 2008, pp. 83-99.

(85)Peña, David. “Fisionomía...” Op. Cit., pp. 304-309.

(86)Ibidem, pp. 469-471.

\section{Enlace alternativo}

http://perio.unlp.edu.ar/ojs/index.php/cps/index (html) 